Revista Água Viva

ISSN 1678-7471

\title{
PENSAR AS CIÊNCIAS HUMANAS COM MIKHAIL BAKHTIN: ALGUNS POSSÍVEIS PERCURSOS DE COMPREENSÃO
}

\section{THINKING HUMAN SCIENCES WITH MIKHAIL BAKHTIN: SOME POSSIBLE UNDERSTANDING COURSES}

\author{
Fábio Marques de Sousa ${ }^{1}$ \\ Ivo Di Camargo $\mathrm{Jr}^{2}$
}

Recebido em: 13 nov. 2019.

Aceito em: 22 fev. 2020.

DOI 10.26512/aguaviva.v5i1.27087

RESUMO: O objetivo desse artigo é proporcionar ao leitor a oportunidade de pensar e problematizar alguns possíveis percursos de compreensão das contribuições de Mikhail Bakhtin e o Círculo para as Ciências Humanas. Para isso, contextualizaremos as ideias do Círculo de Bakhtin, relacionando a produção e construção semântica de cada integrante do grupo russo: Bakhtin, Medvedev, Volochinov, Kanaiev, Pumpianski, Judina, entre outros, que nos proporcionaram uma produção coletiva que até hoje muda as bases do pensamento humanista desenvolvido no ocidente. Estes pesquisadores modificaram sensivelmente os estudos da filosofia da linguagem, estudos de teoria literária, ofereceram uma nova visão para os pensamentos de gêneros do discurso e ofereceram conceitos hoje basilares para os estudos linguísticos e humanos, como a polifonia, alteridade, relações dialógicas, etc. Estes conhecimentos funcionam em relação um com o outro. O que se percebe é um elemento que reuniu em si esse diálogo e que com seu nome promove essa interação entre as áreas do saber, com outros pensadores, pesquisas diversas de autores díspares.

Palavras-chave: Mikhail Bakhtin. Ciências Humanas. Círculo de Bakhtin. Filosofia da Linguagem. Teoria Literária.

\footnotetext{
${ }^{1}$ Professor no Departamento de Letras e Artes e no Programa de Pós-Graduação em Formação de Professores da Universidade Estadual da Paraíba, UEPB. Cursou estágio de pós-doutorado no PPGEduC, da UFPE, com pesquisa a respeito da mediação, com o apoio das Tecnologias Digitais da Informação e Comunicação, do complexo processo de ensino-aprendizagem de línguas adicionais. Mestre (UNESP) e Doutor (USP) em Educação. Licenciado em Letras (Português, Inglês, Espanhol e suas literaturas) e em Pedagogia. E-mail: fabiohispanista@gmail.com

${ }^{2}$ Licenciado em Letras (UNESP), Mestre e Doutor em Linguística (UFSCar). Líder do "Estudos Bakhtinianos" (UNESP) e vice-líder “[d]O Círculo de Bakhtin em diálogo" (UEPB), grupos de pesquisa cadastrados no DGP do CNPq. Desenvolve pesquisas em linguagem cinematográfica e educação. Professor de Língua Portuguesa na rede municipal de ensino de Ribeirão Preto e Sertãozinho-SP. E-mail: $\underline{\text { santacrocce@ gmail.com }}$
} 
RESUMEN: El propósito de este artículo es proporcionar al lector la oportunidad de pensar y discutir algunas formas posibles de comprender las contribuciones de Mikhail Bakhtin y el Círculo para las Humanidades. Para ello, contextualizamos las ideas del Círculo de Bakhtin, relacionando la producción y construcción semántica de cada miembro del grupo ruso: Bakhtin, Medvedev, Volochinov, Kanaiev, Pumpianski, Judina, entre otros, cuya producción colectiva hasta hoy cambia los fundamentos del pensamiento humanista desarrollado en Occidente. Estos investigadores han modificado significativamente los estudios de filosofía del lenguaje, los estudios de la teoría literaria, ofrecieron una nueva visión de los pensamientos de los géneros del discurso y ofrecieron conceptos que ahora son básicos para los estudios lingüísticos y humanos, como la polifonía, la alteridad, las relaciones dialógicas, etc. Este conocimiento funciona en relación el uno con el otro. Lo que se percibe es un elemento que reunió este diálogo y que con su nombre promueve esta interacción entre áreas de conocimiento, con otros pensadores, investigaciones diversas de autores dispares.

Palabras-clave: Mikhail Bakhtin. Ciencias Humanas. Círculo de Bakhtin. Filosofía del lenguaje. Teoría literaria.

Propõe-se neste artigo levar o leitor a pensar e aprofundar o que se pretende aprender. É ir além do que se conhece. O pensamento bakhtiniano traz em si mesmo a necessidade de um mergulho. Este faz com que o leitor tenha de contextualizar as ideias do Círculo de Bakhtin, cujo estudo é o objetivo precípuo desta obra e relacionar a produção e construção semântica de cada integrante do grupo russo. Bakhtin, Medvedev, Volochinov, Kanaiev, Pumpianski, Judina, entre outros, fizeram uma produção coletiva que até hoje muda as bases do pensamento humanista desenvolvido no ocidente.

Estes pesquisadores modificaram sensivelmente os estudos da filosofia da linguagem, estudos de teoria literária, ofereceram uma nova visão para os pensamentos de gêneros do discurso e ofereceram conceitos hoje basilares para os estudos linguísticos e humanos, como a polifonia, alteridade, relações dialógicas, etc. Estes conhecimentos funcionam em relação um com o outro. O que se percebe é um elemento que reuniu em si esse diálogo e que com seu nome promove essa interação entre as áreas do saber, com outros pensadores, pesquisas diversas de autores díspares. Esse nome é o de Mikhail Bakhtin. Ele traz em si a união de diversas vozes que torna difícil uma classificação "estruturalista" do pensamento do Círculo deste pensador russo. Promover um enquadramento de suas ideias seria propor o fim delas. Exterminaria a dialogicidade que é a sua marca e a forma de pensar do Círculo.

O que se afirma aqui é que promover conceitos do estruturalismo dentro do Círculo de Bakhtin seria paradoxal. É o mesmo que acabar com a obra poética de Fernando Pessoa unindo em um só todos os seus heterônimos. Este exemplo em si mesmo é bakhtiniano. A 
complexidade que ocorre dentro do pensamento do Círculo é a sua marca primordial. Não se pretende conseguir reunir tudo em um. Dois é a base de todo pensamento bakhtiniano. Eu e o outro. E daí parte-se para o social.

Ao partir para a reflexão sobre esses temas e pensamentos podemos buscar uma nova forma de ver o humano. Pela dialogia e pela alteridade. Ouvindo a polifonia de vozes existentes dentro de cada um. No Brasil, presente desde o princípio dos anos 1980 com os estudos do ucraniano Boris Schnaiderman, têm-se pesquisas que trazem o diálogo novo e que promoviam interação entre si e com outras teorias, outros pesquisadores. É uma relação que age de dentro para fora, em força centrífuga e de fora para dentro, em força centrípeta. Isso muda a forma de se ver o mundo, com novas relações de tempo, espaço, sujeitos. Tudo isso vem para transformar, reformar, tirar das formas um pensamento que tentava em tudo ser estruturado pela academia ocidental até os anos 1970. Bakhtin e seu círculo, com estes estudos promovidos do final dos anos 1910 até 1975 modifica a vida para uma nova forma de se propor o humanismo, com reflexo e refração, mostrando o eu e o outro que existe dentro de cada sujeito.

\section{Aprofundando os conceitos}

Desenvolver um trabalho que mostre Bakhtin como um pensador relevante e realmente diferente leva a posições de entendimento de concepções dialógicas de linguagem que afetam tanto questões teóricas quanto de análise humana. Em suma, será aqui apresentada uma visão maior pelo aspecto dialógico porque as ideias do Círculo se movem por tantas direções e áreas de estudo que promover uma classificação dos pensamentos de Bakhtin pode reduzir suas ideias a poucos conceitos estruturados e que não dão a devida dimensão aos seus pensamentos.

O diálogo é a base de toda a filosofia da linguagem do Círculo de Bakhtin. Mesmo que alguns pesquisadores mais críticos à teoria bakhtiniana afirmem que não haja um método para estes estudos, considera-se aqui que a dialogia em si é um método tão válido quanto o cartesiano e que o diálogo é imprescindível para a interação de ideias entre os integrantes dos estudos por eles desenvolvidos na Rússia. Eles consideravam a linguagem como um ser vivo em mutação constante e se observar bem os estudos do Círculo pode-se chegar à conclusão que ela não é apenas uma ferramenta de análise e sim a relação entre o que se observa e o observador em si. Bakhtin e seus colegas desenvolveram estudos que construíam ponte e rompiam com os paradigmas, oferecendo olhar para o outro como forma de entendimento para uma realização social mais adequada. 
Bakhtin foi considerado filósofo da linguagem ou linguista, teórico dos estudos literários, estudioso de discurso religioso, historiador de estudos culturais, filósofo, dialogou com Freud em livro e com os formalistas russos. Em sua vida, por muitas décadas, passou incólume pelo status quo de sua época, tendo sofrido algumas vezes devido ao exílio forçado no Cazaquistão, à uma doença grave que lhe custou a amputação de uma perna, ao Estado Soviético em penúria e dificuldades. Talvez seja por isso que estudiosos como Schnaiderman o consideravam uma das personalidades mais abrangentes e inexplicáveis do século passado.

O Círculo Bakhtiniano encontrava-se no centro de uma época efervescente na história russa. Do fim dos anos 1910 aos inícios dos 1930, o país passou por uma revolução que mudou os rumos do século XX. Não se pode nem afirmar a existência de um Círculo sem a amizade produtiva de Bakhtin, Volochinov e Medvedev. Juntos e com outros confrades eles ofereceram uma forma de resistência aos desmandos stalinistas e com trabalhos produzidos em coautoria ou sozinhos, desenvolveram uma nova forma de se ver as ciências humanas no século XX. Dessa forma, compreender a ideia de ideológico ou de signo ideológico dentro de uma obra basilar e ímpar como Marxismo e Filosofia da linguagem mostra a potência desse pensamento porque traz como se reflete e refrata o fenômeno sócio ideológico presente nas sociedades humanas.

Dessa forma, compreender essa noção de signo ideológico traz para o estudioso o cerne do pensamento do Círculo de Bakhtin, pois demonstra o caráter material de todo acontecimento ideológico. Bakhtin e Volochinov já afirmavam que a ideologia é demonstrada pelo material semiótico e tudo o que é expresso ou em sua possibilidade de ser expressado trará em si um valor ideológico. A palavra, um texto, o discurso, tudo isto traz critérios de seu próprio acontecimento. A entoação pode ser uma forma de variedade ideológica. Traz em si um caráter diferente porque seres humanos diferentes podem utilizar-se da mesma linguagem para dizer coisas diversas. Assim, o signo ideológico encontrará expressões de valor ou caráter ideológicos em si mesmo. Poderão demonstrar o vivido, seja individual ou coletivo, como uma forma de assunção ou oposição. Pode ser monológico ou dialógico, polifônico. Em todas estas concepções, o Círculo de Bakhtin ofereceu sua contribuição por meio dos valores da sociedade, com sua ideologia presente e em coletividade.

As obras do Círculo de Bakhtin foram apresentadas no cenário ocidental nos anos 1960 quando Julia Kristeva traz da Bulgária estudos do pensador russo sobre literatura. A força dos estudos do Círculo foi utilizada em diversas pesquisas até que Jacqueline Authier-Revuz aprofundou-se em seus estudos e desenvolveu nos anos 1980 o conceito de "heterogeneidade 
mostrada" e "heterogeneidade constituída", em texto de 1982. A autora francesa apresentou uma extensão dos estudos oferecidos pelo Círculo no tocante à presença e evidencia do outro dentro do discurso. Isso pode levar a pensar nos estudos de Foucault e Pêcheux como dialogantes, mesmo que o segundo tenha recusado esse diálogo em um primeiro momento. Somente no final de seus escritos, já também nos anos 1980 que o francês admitiu ideias do Círculo pelo olhar da dialogia, contudo, em poucos e raros momentos de seu trabalho sobre discurso, estrutura ou acontecimento.

Dessa maneira, pode-se evoluir um pensamento e procurar dentro da AD Francesa e se ambos se desenvolveram um pelo outro ou um é fruto do outro? Considerando a história, é impossível Bakhtin ser considerado dentro da AD Francesa. Enquanto o Círculo de Bakhtin desenvolveu seus estudos no início do século XX e Bakhtin ao longo de todo este, os estudos franceses apenas se iniciaram nos anos 1960 e tiveram seu auge nos anos 1980. Por isso, a força do pensamento do Círculo é mais uma forma de diálogo com outra teoria e mesmo que haja diferenças e contradições entre elas, isto faz parte do pensamento do Círculo de haver sempre o diálogo, as vozes, a diferença que mais constitui do que promove desigualdade.

No Brasil, o livro Marxismo e Filosofia da Linguagem, publicado originalmente em 1929 por Volochinov, foi traduzido direto do francês em 1981, mas somente no final desta década e no início dos anos 1990 que Bakhtin, ainda sem o Círculo, começa a ser discutido como um teórico forte e sendo aceito pela academia nacional. Dentro da pedagogia, que já aceitava as contribuições do conterrâneo de Bakhtin, o psicólogo Vigotski, acata pensamentos do teórico do Círculo. As ciências sociais conseguem perceber na obra referida um marxismo que presenciou a massificação da censura soviética tanto na vida quanto na obra. Isso também foi percebido pela história.

Em 1929, Bakhtin publica seu livro intitulado Problemas da Poética de Dostoievski, que seria relançado apenas 34 anos depois. Esta obra saiu com o nome do mestre russo e trata pela primeira vez da temática do romance polifônico, colocando Dostoievski como o autor criador deste tipo de romance, onde várias vozes ideológicas contraditórias existiriam no narrador e personagens da obra. Dentro da produção da teoria literária, Bakhtin publica, anos depois, a sua tese de doutorado, que foi escrita em 1940 e defendida em 1951, após inúmeras discussões da banca examinadora, que aprovou o texto, mas negou-lhe o título de doutor. A obra A Cultura Popular na Idade Média e no Renascimento: o contexto de François Rabelais trouxe a elaboração do conceito de carnavalização colocando o riso como poder que demolia as convenções sociais engessadas e revelava na linguagem os conflitos existentes na sociedade. 
Uma obra que saiu no ano da morte de Bakhtin, Questões de literatura e estética reunia textos dos anos 1930 que tratavam das questões de autoria, estilo e teorizações sobre o conceito do herói. Essas obras colocaram Bakhtin no patamar de autor respeitado em teoria literária e o legitimou como autor dentro dessa categoria.

Assim, com o tempo, mais e mais "Bakhtins" foram surgindo e desenvolvendo uma personalidade sofisticada nos estudos humanos, principalmente da literatura. Contudo, nesse mesmo ínterim, começou a surgir uma suspeita sobre a questão da autoria dos textos publicados por Bakhtin. E, concomitantemente, também surgiam outros textos inéditos escritos por ele nos anos 1930/40. Esses trabalhos se vinculavam a uma visão mais ligada à filosofia da linguagem e literatura, tendo, inclusive, textos considerados diferentes, como no caso do tex to Vitalismo contemporâneo, sobre forma fisiológica do cérebro, assinado por I. I. Kanaiev e publicado em 1926 e o livro "O Freudismo", assinado por Volochinov e publicado em 1927. Este é um dos debates escritos por eles no Círculo que desenvolviam diálogos com base numa teoria linguística.

Com toda essa oferta de estudos e trabalhos que surgiram no ambiente intelectual ao longo dos anos, foi natural considerar que erros interpretativos e de análise ocorressem, isso porque, a sua obra não tinha sido toda analisada como se deve. Se observar apenas o surgimento de seus trabalhos no ocidente, provindos de estudos literários, filosóficos e da linguagem, podese compreender o motivo pelo qual seus trabalhos obtiveram tamanho êxito em diversas áreas do saber. Na área da linguagem, dominavam o cenário Saussure e Chomsky. Bakhtin, com os diálogos que sua teoria oferecia promoveu uma humanização mais arejada na área. Na literatura o estruturalismo, em uma dominância dividida com o formalismo, obteve com os estudos bakhtinianos uma liberdade maior de vozes, uma nova forma de perceber que personagens e autores poderiam oferecer e receber do leitor muito mais do que era visto até o momento, com uma divisão dos romances em monológicos e polifônicos. A literatura, com Bakhtin e o Círculo, passou a ser vista como uma relação maior com sua inscrição dentro do social e da história, apreendendo muito mais do contexto ideológico e humano na qual estava inserida.

Nesse contexto intelectual, surgem os estudos que ampliaram o trabalho do Círculo. Escritos de Kristeva, Authier-Revuz, a biografia produzida por Clark e Holquist, trouxeram olhares para o trabalho de Bakhtin e seu círculo de autores que mudou as ciências humanas para sempre. O Círculo vai passar a ser considerado, nas humanidades, um estudo necessário e quase obrigatório para os que desejam aprofundar os olhares para um estudo que oferece visão concentrada no outro e como isso modifica a sociedade. 
Bakhtin e os estudos do Círculo nos direcionam a duas posições que são a relação entre os interacionistas, que são interlocutores que vão interagir entre si e com outros sujeitos da sociedade. Para Bakhtin os estudos produzidos pelo olhar interacionista promovem uma humanização maior e uma sociologização mais abrangente; para o mestre russo, um discurso não é jamais individual porque vai ser desenvolvido entre dois ou mais interlocutores. Não pode ser individual, já que a interação necessita de dois ou mais sujeitos ou discursos. Dentro do que se conhece de Linguística Textual, por exemplo, um texto para ser desenvolvido e recebido pelos leitores, é necessário que haja um conhecimento prévio dos textos que compuseram essa interação momentânea, seja na vida do leitor ou do produtor dos textos.

Há vários eventos acadêmicos e científicos, sejam eles no Brasil ou exterior que se utilizam dos ensinamentos e desenvolvimentos intelectuais de Bakhtin e seu círculo e isso comprova a validade de sua obra. Grupos de pesquisa são de muitos países afora. Há que se entender que esse interesse está presente em muitos pesquisadores que buscam cada vez mais desenvolver seus trabalhos. Dessa maneira, publicar este artigo que sintetiza o valor humano dos conceitos bakhtinianos traz a possibilidade de se mostrar ao leitor um cenário crescente de interesse por questões sociais e ideológicas que priorizem o diálogo como questão humana. Isso nos faz compreender o valor de Bakhtin como cientista da linguagem, da literatura e da filosofia. Único e dialogicamente heterogêneo.

\section{Justificativas intelectuais}

Este artigo pretendeu evidenciar a importância da circulação dos estudos do Círculo de Bakhtin e demonstrar a sua importância como pensadores das ciências humanas. Quando se verifica a quantidade de áreas do intelecto humano que consideram Bakhtin e seu círculo um referencial para pesquisas, percebe-se que as relações dialógicas da linguagem fazem de Bakhtin um autor conceitual que com seu grupo promove o debate intelectual entre áreas e pesquisadores de segmentos diversos.

Publicar este texto se justifica pela questão de legitimar o pensador russo e seus associados como essenciais para o campo das humanidades. Acredita-se que o diálogo realizado nessa discussão, abrangendo muitas áreas do conhecimento humano, garantirão uma nova forma de se perceber Bakhtin e seu círculo como autores cujo desenvolvimento das ideias ocorre principalmente de maneira transdisciplinar. Dessa maneira, o que se evidencia é promover a reflexão e refração das ideias do grupo, de modo que não se enquadrem somente numa área do conhecimento. É necessário que os textos abordados proponham-se a tratar dos 
conceitos bakhtinianos de modo a oferecer um pensamento abrangente em suas filosofias e produções intelectuais.

Outro ponto de vista relevante pode ser encontrado na forma como os conceitos bakhtinianos são móveis e transitam por áreas diversas. Isso evidenciará a concepção dialógica da linguagem e por este motivo uma análise sobre como ocorreu o desenvolvimento e embate entre o estruturalismo e as relações dialógicas bakhtinianas ainda é necessária em análises que procurem uma evolução do humanismo nos estudos do ocidente.

Para a questão histórica, observa-se quanto é especial para estre momento considerar a produção bakhtiniana e de seu círculo na Rússia, no mundo ocidental e aqui no Brasil. Percebese o intuito de construir um passado, valorizando o presente de trabalhos e projetando um futuro adequado para mais estudos abrangentes. Se uma análise for feita desde a divulgação dos estudos do Círculo percebe-se uma profundidade contínua que faz com que esta se firme como uma área relevante e cada vez mais com aquilo que os críticos tanto menosprezam por desconhecimento da teoria: a falta de um método. Não compreendem eles que os escritos bakhtinianos todos e do Círculo têm um método que escapa a uma obra só e podem ser encontrados na leitura ampla e contextualizada dos escritos.

Observe-se também que áreas que eram concorrentes aos estudos do Círculo de Bakhtin até décadas atrás, como, por exemplo, a Análise do Discurso de linha francesa, hoje dialogam com os estudos bakhtinianos em forte pesquisa acadêmica que com seus projetos trazem benefícios para a sociedade, com um entendimento mais claro e preciso, revelando nuances que antes eram esquecidas ou apagadas da memória coletiva. No campo literário, temas como as poéticas, questões de autoria, de estilo, o reconhecimento da carnavalização nos textos, conceitos de cronotopia e exotopia, enfim, muitos outros que hoje passaram a ser considerados imprescindíveis para uma análise literária séria e competente na teoria da literatura.

No campo pedagógico, a pesquisa com conceitos do Círculo é produtiva porque a inserção de Bakhtin dentro dos Parâmetros Curriculares Nacionais, em especial com a questão do gênero do discurso, trouxe um novo olhar para a prática educacional, sendo ponto constante nas escolas e, principalmente, questões em concursos públicos de forma presente, o que denota uma importância para a área, porque entra na fase de seleção de futuros docentes pelo país afora.

Há que se ressaltar a vertente filosófica do discurso e do humanismo onde Bakhtin e Volochinov afirmavam que a palavra era "o modo mais puro e sensível de relação social” (2006, 
p. 36). Se analisarmos essa questão, percebe-se uma visão discursiva da vida, que é a base constituinte da visão de sujeito de Bakhtin e seu círculo.

Assim, a forma de pensar que este artigo pretendeu transmitir é uma forma de ver Bakhtin e seu Círculo como produtores de um conhecimento amplo e multidisciplinar que deve ser analisado de maneira a não esgotar o seu potencial e disseminar um conhecimento dialógico e de caráter polifônico que faz dos russos do Círculo de Bakhtin autores especiais e especializados em promover diálogos, debates, alteridade e promoção da diferença como motivo de evolução para a sociedade humana.

\section{REFERÊNCIAS}

BAKHTIN, M./VOLOCHINOV. Marxismo e Filosofia da Linguagem. Tradução de Carlos Alberto Faraco. São Paulo: Hucitec, 2006.

BAKHTIN, M./VOLOCHINOV. Discurso na vida e discurso na arte. Tradução de Carlos Alberto Faraco). São Paulo: Hucitec, 2006 [1926].

BAKHTIN, M. Estética da Criação Verbal. São Paulo: Martins Fontes, 1992.

BAKHTIN, M./VOLOCHINOV. Problemas da poética de Dostoiévski. Rio de Janeiro: Forense-Universitária, 1981.

BAKHTIN, M./VOLOCHINOV. A cultura popular na Idade Média e no Renascimento: o contexto de François Rabelais. São Paulo: Hucitec, 1987.

BAKHTIN, M./VOLOCHINOV. Questões de literatura e estética: a teoria do romance. São Paulo: Hucitec/ USP, 1988.

BAKHTIN, M./VOLOCHINOV. O Freudismo. São Paulo: Perspectiva, 2004

BEZERRA, P. Prefácio à segunda edição brasileira. In: BAKHTIN, M. Problemas da poética de Dostoievski. Rio de Janeiro: Forense Universitária, 1981.

BRAIT, B. (Org.). Bakhtin - conceitos-chave. São Paulo: Contexto, 2005.

BRAIT, B. Bakhtin - outros conceitos-chave. São Paulo: Contexto, 2006.

BRAIT, B. Análise e teoria do discurso. In: BRAIT, B. (Org.). Bakhtin - outros conceitoschave. São Paulo: Contexto, 2006.

CLARK, K.; HOLQUIST, M. Mikhail Bakhtin. São Paulo: Perspectiva, 1998.

DI CAMARGO, Ivo Jr. Mikhail Bakhtin na linguagem cinematográfica. São Paulo: Mentes Abertas, 2020 [no prelo]. 
DI CAMARGO, Ivo Jr. A Memória de Futuro analisada pela Linguagem

Cinematográfica: diálogos entre a Teoria do Cinema e Mikhail Bakhtin. São Paulo: Mentes Abertas, 2020 [no prelo].

MIOTELLO, V. Bakhtin em trabalhos de estudo da língua: levantando o problema do pertencimento. Estudos Linguísticos, Campinas, v. XXXV, p. 176-180, 2006.

MIOTELlO, V. Discutindo a questão do dialogismo com Bakhtin. Versão Beta, São Carlos, n. 25, p. 31-50, 2003.

MIOTELLO, V. Compreendendo alguns conceitos bakhtinianos. Versão Beta, São Carlos/SP, n. 10, 2002, p. 02-10.

MIOTELLO, V. Estudo da língua em Bakhtin - objeto e metodologia. In: Sandra Regina Buttros Gattolin; Mônica Baltazar Diniz Signori; Valdemir Miotello. (Org.). Década - Dez anos entre o aprender e o ensinar linguagens. São Carlos/SP: Pedro \& João Editores, 2007.

MIOTELLO, V. As palavras engravidam e grávidas dão à luz um mundo novo. In: Grupo de Estudos dos Gêneros do Discurso - GEGE. (Org.). O Espelho de Bakhtin. São Carlos/SP: Pedro \& João Editores, 2007.

MIOTELLO, V. A Memória do Passado em jogo com a Memória do Futuro constitui sentidos agora. Daí que os Projetos de Dizer dos sujeitos têm importância. In: André Luiz Covre, Fabrício de Oliveira, Valdemir Miotello e outros. (Org.). Veredas Bakhtinianas - de objetos a sujeitos. São Carlos: Pedro \& João Editores, 2006.

MIOTELLO, V. Ideologia. In: Beth Brait. (Org.). Bakhtin - Conceitos-chave. São Paulo: Editora Contexto, 2005, p. 167-177.

PONZIO, A. La revolución bajtiniana. Madri: Catedra, 1999.

PONZIO, A. A Revolução Bakhtiniana. São Paulo; Editora Contexto, 2008. 